\title{
Contribuições do Desenvolvimento Histórico-Cultural dos Conceitos de Ácido e de Base para o Ensino de Química
}

\section{Contributions of the Cultural-Historical Development of Acid and Base Concepts for Chemistry Teaching}

\author{
Cintia Maria Carneiro Franco Lima \\ Brasil \\ José Luis de Paula Barros Silva \\ Brasil
}

Este trabalho tem como objetivo contribuir para superar a fragmentação constatada no ensino dos conceitos de ácido e base, explicitando as razões para sua elaboração e as relações entre os diferentes conceitos ao longo do seu desenvolvimento histórico-cultural. A análise de conteúdo de fontes históricas primárias e secundárias realizada com base na teoria histórico-cultural mostra que tais conceitos se desenvolveram em quatro fases, caracterizados por: propriedades empíricas, composição química, composição e reações de dissociação e/ou associação, estrutura atômico-molecular e reações de adição. Tais resultados sugerem que o ensino siga o desenvolvimento dos conceitos de modo que os estudantes possam compreender os vários processos de elaboração conceitual e suas relações, atentando para as diferentes características atribuídas aos materiais, tanto empíricas quanto teóricas. Ademais, o ensino pode contribuir para a compreensão do caráter teórico e abstrato dos conceitos de ácido e base e dos seus variados graus de generalidade, associados à sua capacidade de discriminação e sua utilidade para a classificação das substâncias. Sugere-se a continuidade da pesquisa.

Palavras-chave: conceitos ácido-base; teoria histórico-cultural; ensino de química.

This paper aims to devise ways to overcome the fragmentation observed in the teaching of acid and base concepts, explaining the reasons for their elaboration and the relationships between the different concepts through its cultural-historical development. We carried out an analysis of the content of primary and secondary historical sources based on cultural-historical theory, which showed that these concepts develop in four phases, characterized by: empirical properties, chemical composition, composition and dissociation and/or association reactions, atomic-molecular structure and addition reactions. Such results suggest that teaching should follow the development of concepts so that students can understand the various processes of conceptual elaboration and their relationships, paying attention to the different characteristics attributed to materials, both empirical and theoretical. Furthermore, teaching can contribute to the understanding of the theoretical and abstract character of acid and base concepts and their varying degrees of generality, associated with their capacity for discrimination and 
their usefulness for substances classification. Finally, we encourage further integration of this research.

Keywords: acid-base concepts; historical-cultural theory; teaching chemistry.

\section{Introdução}

Ácido e base são conceitos antigos cuja origem se confunde com a própria origem da Química, mas que se modificaram ao longo dos séculos (Nunes; Dantas; Oliveira, \& Hussein, 2016).

A relevância dos conceitos de ácido e de base para o ensino da Química atual pode ser constatada pelos seguintes fatos: (a) são conteúdos oficialmente recomendados para a Educação Básica (Ciências, 2006); (b) são conteúdos de destaque nas disciplinas de Química Básica para Cursos de Química, conforme se constata nas bibliografias básicas para essas disciplinas (p. ex.: Atkins, Jones, \& Laverman, 2018; Chang, \& Golsby, 2013); (c) uma grande quantidade de artigos acerca do seu ensino tem sido publicada: busca realizada na base ERIC - Education Resources Information Center com a palavrachave acid revelou a existência de 259 artigos nos últimos 5 anos; com o termo restrito a acid-base, a quantidade foi reduzida para 69 artigos nos mesmos 5 anos, o que constitui, ainda, uma grande quantidade, correspondente à publicação de mais de um artigo por mês; (d) o tema também tem sido objeto de constante presença nas publicações nacionais de Ensino de Ciências/Química, embora de modo não tão numeroso.

Entretanto, as discussões realizadas nesses artigos carecem de esclarecimentos acerca das razões em que se baseiam os conceitos de ácido e de base. De modo geral, os diversos conceitos são apresentados prontos e acabados, sem conexão entre si e sem explicitação dos motivos e argumentos empregados na sua elaboração. Até trabalhos que apresentam o desenvolvimento histórico dos conceitos de ácido e de base (por exemplo: Bell, 1947; Chagas, 2000; Jensen, 2016a; Silva, \& Santiago, 2012; Souza, \& Aricó, 2017; Souza, \& Silva, 2018) não apresentam clareza acerca das elaborações conceituais nem dos motivos que levaram às modificações propostas ao longo do tempo.

Chagas (2000), por exemplo, após um preâmbulo composto por um conjunto de informações não claramente conectadas acerca de ácidos e bases ao longo dos séculos, apresenta várias teorias do século XX, iniciando pela de Arrhenius. Segundo o autor, tal teoria "abrangeu um grande número de fatos conhecidos e possibilitou o surgimento de várias linhas de pesquisa” (p. 128). Uma vez que os fatos e as linhas de pesquisa não foram apresentados, a afirmação constitui-se em argumento de autoridade que pode até ser aceito, mas não convence. Chagas (2000) também sugere que novas teorias surgiram quando a teoria anterior "foi se mostrando incapaz de dar conta" de "novos resultados [que] foram se acumulando" (p. 128). Porém, ao longo do texto, passa de uma teoria a outra sem exibir os resultados acumulados que se tornaram problemas, ou discutir como as novas teorias resolveram os problemas.

Essas falhas também são encontradas em materiais didáticos, tanto para o Ensino 
Superior (por exemplo: Atkins, Jones, \& Laverman, 2018; Chang, \& Golsby, 2013) quanto para o Ensino Médio (por exemplo: Fonseca, 2016; Novais, \& Antunes, 2016).

Atkins, Jones e Laverman (2018) apresentam os conceitos sem qualquer razão para sua elaboração, como se tivessem sido descobertos ou desvelados. Os autores apontam que a importância da teoria ácido-base de Arrhenius está na sua utilidade e defendem que na passagem dessa teoria para a de Brönsted-Lowry e para a teoria Lewis, há um aumento da amplitude conceitual, aludindo à possibilidade de um ganho nessas mudanças, o qual não fica claro. Ora, toda teoria tem alguma utilidade e conforme discutimos adiante, o ganho em amplitude diminui o poder discriminatório do conceito e conduz à perda de sua capacidade classificatória.

Em vista do exposto, o que se observa é um conjunto de diferentes conceitos de ácido e base, prontos e acabados, sem vínculo entre si, de modo que o ensino se apresenta fragmentado. Porém, concordamos com a teoria histórico-cultural (Vigotski, 2009), segundo a qual conceitos são elaborados sistematicamente, de modo que a aprendizagem de um novo conceito requer a compreensão de sua relação com outros conceitos vinculados aos problemas e argumentos que levaram à sua formulação.

Por outro lado, a História da Ciência (Beltran, Saito, \& Trindade, 2014) pode tornar explícitos tais problemas e argumentos, pois mostra que os conceitos elaborados por cientistas são fruto de raciocínios que se desenvolvem dentro de um contexto social, a partir de contribuições diversas que constituem pressupostos teóricos e/ou dados empíricos e que visam atender às necessidades dos seres humanos.

Em vista do exposto, este trabalho se propõe a responder a seguinte questão de pesquisa: o desenvolvimento histórico-cultural dos conceitos de ácido e base pode contribuir para superar a fragmentação constatada no seu ensino, explicitando as razões para sua elaboração e as relações entre os diferentes conceitos ao longo do tempo?

Essa questão pode ser traduzida no objetivo do artigo de contribuir para superar a fragmentação constatada no ensino dos conceitos de ácido e base, explicitando as razões para sua elaboração e as relações entre os diferentes conceitos ao longo do seu desenvolvimento histórico-cultural.

Posto o problema e o objetivo, nosso argumento se desenvolve do seguinte modo: apresentação dos pressupostos teóricos que orientam a pesquisa, seguida da metodologia de pesquisa, dos resultados e suas contribuições para superar a fragmentação do ensino e, por fim, as conclusões.

\section{Conceitos em Perspectiva Histórico-Cultural}

Partimos do pressuposto de que o ser humano vive em um mundo que lhe é externo e independente, constituído por objetos, situações, eventos, além dos demais seres humanos, conforme nos revelam os órgãos dos sentidos e o senso comum.

Por outro lado, cada ser humano possui uma interioridade reflexiva (Ferreira, 2008), na qual se entrelaçam desejos, sentimentos, sensações, percepções e memórias relativos ao mundo e a si próprio (Luria, 1979). Tal interioridade se manifesta por meio 
das ações dos seres humanos frente ao mundo e aos seus semelhantes.

Situado no mundo, o ser humano interage com seu entorno e consigo mesmo por meio dos órgãos dos sentidos, obtendo o que se convencionou denominar sensações. Sensações são, portanto, processos internos resultantes de acontecimentos externos e internos captados pelo corpo humano. Os órgãos dos sentidos não atuam isoladamente, mas de modo conjunto, fazendo com que as várias sensações se integrem em estruturas complexas: as percepções. Tanto umas quanto outras são passíveis de serem conservadas na memória e recuperadas posteriormente, combinadas em novas percepções e correlações para formar estruturas ainda mais complexas: conceitos e pensamentos (Luria, 1979). Portanto, todo conceito nasce da necessidade de o ser humano interagir com o mundo, compreendê-lo, transformá-lo. As dificuldades advindas dessa necessidade criam problemas e os conceitos são formados e/ou aprendidos nas tentativas de solucionar esses problemas (Vigotski, 2009), conforme discutimos a seguir.

Um conceito (ou significado) é um processo de elaboração humana, "uma atividade criadora que permite inventar novas maneiras de pensar, de sentir, de ver (conceber, perceber), de compreender o incompreensível” (Ferreira, 2013, p. 10). Em outras palavras, conceito constitui-se em "todo processo que torne possível a descrição, a classificação e a previsão dos objetos cognoscíveis" (Abbagnano, 2007, p. 164). Enquanto produto, conceito é entendido como unidade do pensamento(Ferrater Mora, 1964; Hardy-Vallé, 2013), mas também, como unidade cultural — "Em qualquer cultura, uma unidade cultural é simplesmente algo que aquela cultura definiu como unidade distinta, diversa de outras [...]" (Eco, 2009, p. 56-57) - de modo que um pensamento é uma correlação entre conceitos, cada qual carregado de emoções, lembranças, desejos e percepções acerca do mundo.

O pensamento se realiza por meio da linguagem (Vigotski, 2009): "É o que se pode dizer que delimita e organiza o que se pode pensar" (Benveniste, 1976, p. 76, grifo do autor). Quando um conjunto de expressões linguísticas (ou de algum outro código) organizadas de modo intencional é apresentado publicamente por alguém e em determinado contexto, o pensamento se concretiza e adquire realidade, porque só então pode ser conhecido e, quiçá, compreendido por outros seres humanos.

As expressões linguísticas e não linguísticas veiculam conceitos como seus conteúdos. Ou, de outro modo: signos (expressões ou termos conceituais) expressam significados (conceitos, conteúdos dos signos). Quando signos são combinados de acordo com regras socialmente pré-estabelecidas, formam signos e significados mais complexos. Assim, um conceito pode ser expresso tanto por uma palavra quanto por uma locução, uma frase, um parágrafo ou um texto inteiro (Abbagnano, 2007). Falase, por exemplo, do conceito de ácido sabendo-se que, para compreendê-lo, é preciso conhecer um conjunto de teorias que podem ocupar uma grande quantidade de páginas escritas.

As relações entre expressão/signo e conceito/significado podem ser estabelecidas de muitos modos, sendo os mais comuns a convenção arbitrária, a semelhança e a analogia 
em relação a outro conceito e/ou objeto, situação ou evento. $\mathrm{O}$ conceito propriamente dito é explicitado por meio de suas características distintivas (Vigotski, 2009), as quais se encontram vinculadas aos casos - objetos, situações, eventos - que constituem os problemas que dão origem ao conceito. Então, o conceito do número cinco é indicador de quantidade, maior do que 4 e menor do que 6, que pode ser usado como valor de uma medida ou um indicador de ordem, entre a $4^{\mathrm{a}}$ e a $6^{\mathrm{a}}$ posição. Coisas em quantidade são encontradas à nossa volta, medidas fazem parte do nosso dia a dia e a ordenação das coisas e ações está presente em nosso comportamento, de modo que o número cinco nos auxilia a compreender o mundo e a sociedade, ao resolver os problemas de como identificar e comparar quantidades e como ordenar coisas e procedimentos. De modo análogo, o conhecimento do conceito de dióxido de carbono pode nos auxiliar a compreender o aquecimento global, a chuva ácida e seus efeitos sobre a natureza e as edificações, a asfixia etc.

Notemos que os casos aos quais os conceitos se referem podem ser concretos, no sentido de empíricos, sensíveis (cinco colheres, um cilindro cheio com dióxido de carbono) ou abstratos (cinco lembranças, moléculas de dióxido de carbono). Podem ser reais, mesmo que não observáveis (os sentimentos) ou simplesmente idealizados (um centauro). Portanto, as características constituintes do conceito funcionam como uma descrição daquilo a que ele se refere (Abbagnano, 2007; Hardy-Vallée, 2013), embora não necessariamente real, como no caso de um centauro, e/ou completa, como no caso dos sentimentos. Também funcionam como critérios para conceituar novos casos, pois só serão incluídos no conceito os casos que tiverem descrição semelhante.

Em vista do exposto, notamos que contribuem para a elaboração de um conceito aspectos externos ao ser humano (objetos, situações, eventos do mundo, aos quais o conceito se refere), aspectos internos (sensações, percepção, memória, sentimentos, desejos, pensamentos etc.), expressivos, linguísticos ou não (línguas naturais e outros códigos), condicionados por aspectos biológicos (órgãos de interação com o mundo) e imersos nas relações dos interlocutores. Logo, a aprendizagem de um conceito dependerá da aprendizagem de como lidar com esses mesmos aspectos.

De acordo com a teoria histórico-cultural, "a grande maioria dos conhecimentos e habilidades do homem se forma por meio da assimilação da experiência de toda a humanidade, acumulada no processo da história social e transmissível no processo de aprendizagem" (Luria, 1991, p. 73). Os conhecimentos são transmitidos de geração em geração por meio da comunicação entre seres humanos, que é, em princípio, sempre significativa, conceitual (Eco, 2009), mas, não imediatamente compreensível. Se o significado de um signo não é compreendido, este é percebido, apenas, como um sinal (rabisco, som etc.): a comunicação conceitual não se efetiva e a aprendizagem se restringe à expressão vazia. A compreensão do conteúdo de ensino e sua aprendizagem por seres humanos se dá por meio da interpretação dos signos e das intenções do/a interlocutor/a (professor/a, livro didático, colega etc.) ao apresentar o conteúdo. A interpretação parte dos possíveis significados diretos do signo - que dependem do conhecimento 
que o aprendiz já possui acerca do conteúdo em pauta - e, empregando instrumentos sensoriais e psicológicos, investiga sua coerência com o contexto da comunicação, considerando o modo como o/a interlocutor/a apresenta o conteúdo para concluir se há outros significados não explícitos (Dascal, 2006).

Em termos psicológicos, a aprendizagem de conceito é um processo de desenvolvimento de estruturas psíquicas do ser humano, as quais são independentes dos elementos específicos que as constituem, de modo que os aspectos gerais podem ser transferidos para outras experiências que guardem similaridade com aquelas que as geraram. Por isso, o conhecimento de um signo aprendido em dada situação pode ser transferido para outras situações, fazendo com que a estrutura se generalize e se desenvolva (Vigotski, 2009). Uma outra situação na qual a estrutura psíquica se desenvolve e generaliza ocorre quando um signo muda de significado e ganha mais conteúdo, como ocorreu no caso dos signos ácido e base ao longo do tempo (ver abaixo).

No processo ontogenético de formação de conceito (Vigotski, 2009) verifica-se que o termo conceitual vai ganhando generalidade cada vez maior: uma criança pequena aprende o termo colher a partir do objeto que é usado para lhe alimentar, ou seja: de início, o nome designa apenas um objeto. À medida que a criança vai aumentando suas experiências no mundo, essas criam problemas que são motivos para mudanças conceituais, de modo que o mesmo nome passa a ser empregado com diferentes objetos que têm em comum o uso na alimentação. O termo colher passa a designar muitos objetos, generalizando-se. Para tanto, os traços distintivos do conceito mudam e/ou sofrem redução: se a primeira colher era reconhecida por seu uso, forma, material, tamanho e cores, tais características não contam para os diferentes objetos que passaram a ser posteriormente reconhecidos como colheres. Os traços que distinguem uma colher se reduzem ao seu uso na alimentação e à sua forma de concha.

A generalização atinge o seu grau máximo quando o ser humano passa a pensar e agir em nível abstrato, sem recorrer às experiências concretas vinculadas às estruturas psíquicas e aos conceitos com que opera, embora resquícios dessas experiências permaneçam na memória. A generalização faz com que a descrição produzida pelo conceito não corresponda exatamente a nenhum dos casos aos quais se aplica, mas a todos simultaneamente. Desse modo, o conceito funciona como classe ou categoria, agrupando sob sua expressão todos os casos que possuem em comum determinadas características. Assim, as características distintivas de um conceito tornam-se critérios para a identificação de outros casos que possam ser inseridos na classe, funcionando, também, como instrumentos de predição (Abbagnano, 2007; Hardy-Vallée, 2013).

\section{Metodologia}

Trata-se de pesquisa documental qualitativa. Tendo como pressupostos que: (a) a aprendizagem de um novo conceito requer a compreensão dos motivos e dos argumentos que levaram à sua formulação; e (b) a História da Ciência pode tornar explícitos tais motivos e argumentos, buscamos identificar os problemas que deram origem a cada 
conceito de ácido e álcali ou base, assim como os raciocínios que justificaram cada tentativa de solução desses problemas ao longo do tempo, por meio da análise de conteúdo (Bardin, 1970) de fontes históricas primárias e secundárias de História da Química.

Durante a pré-análise, foram selecionados textos representativos de História da Química: Brock (2000); Crosland (1978); Debus (2002); Goldfarb (2005); Ihde (1974); Leicester (1956); Partington (1961; 1962; 1964); Siegfried (2002). Também incluímos a tradução brasileira do Tratado de Lavoisier (2007), conhecido por sua teoria dos ácidos e alguns artigos acerca da história de ácidos e bases: Chagas (2000); Silva e Santiago (2012).

Orientada pela noção de conceito da teoria histórico-cultural exposta na seção precedente, a análise teve como objetivos identificar em cada conceito de ácido, álcali ou base: o problema que lhe deu origem; suas características; seus sucessos e suas limitações, ao serem empregados em situações concretas. Para alcançar esses objetivos, os textos selecionados foram recortados em unidades que expressavam os seguintes aspectos descritivos dos materiais considerados como ácidos, álcalis ou bases: sensações provocadas em seres humanos; interações com outros materiais e com organismos vivos; expressões linguísticas relativas às suas características; explicações de casos exemplares (objetos, situações, eventos); limitações dos conceitos; inferências teóricas e suas relações com dados empíricos; relações explícitas entre os conceitos. Também buscamos identificar, tanto quanto possível, os encadeamentos dos raciocínios (argumentos) empregados na formulação e no emprego de cada conceito de ácido, álcali ou base, os quais deveriam expressar os modos como esses conceitos resolveriam os problemas apontados.

Vários dos achados na fase inicial da análise geraram outros termos de busca para seu esclarecimento (p. ex.: Macquer, história dos indicadores ácido-base, solvo ácidos e bases), nos remetendo ao exame de outras obras, principalmente fontes primárias citadas nos textos de História da Química. Quando as fontes primárias não estavam disponíveis, procuramos empregar outras fontes secundárias.

Os recortes foram inicialmente classificados em dois grandes blocos: conceitos empíricos e conceitos teóricos, os quais foram subdivididos para dar origem às diversas fases do desenvolvimento conceitual histórico-cultural apresentado a seguir.

\section{Desenvolvimento Histórico-Cultural dos Conceitos de Ácido e Base}

\section{Pré-Conceitos de Ácido e de Álcali}

Registros acerca de materiais hoje identificados como ácidos e álcalis são conhecidos há muito tempo: artesãos, sacerdotes e alquimistas utilizaram tais materiais. Porém, seu conhecimento se resumia a casos que não formavam classes (Brock, 2000; Leicester, 1956; Silva, \& Santiago, 2012). 
O termo ácido, nas línguas latinas e inglesa (acid), tem suas raízes mais profundas no latim, idioma em que o antepositivo ac-denotava "picante, agudo, pontudo" e deu origem aos termos acidum, acidus, entre outros relacionados ao sabor azedo (Acid, 2019; Acide, 2013; Ácido, 2001). Da antiguidade ao século XVI, o termo ácido era um adjetivo restrito a poucos materiais de origem natural a exemplos do vinagre, leite azedo e alguns sucos de frutas (Ihde, 1984; Leicester, 1956).

Álcali deriva do árabe al-qalyi por intermédio do latim alcali ou alkali (Álcali, 1999), com o significado original de cinzas vegetais (Alkalies, 1929). Assim, o termo álcali nasceu como substantivo, embora de uso restrito a poucos materiais. Portanto, o primeiro conceito de álcali foi material derivado de cinzas vegetais, também caracterizado pelo sabor amargo (Crosland, 1978).

Materiais hoje reconhecidos como ácidos minerais - ácidos nítrico, sulfúrico, clorídrico e água régia - foram preparados entre os séculos XIII e XVI. Tal descoberta ampliou a possibilidade de dissolver substâncias e realizar reações em solução, representando um avanço em relação aos materiais ácidos de origem orgânica - vinagre, leite azedo, sucos de frutas - conhecidos até então (Ihde, 1984; Leicester, 1956).

O século XVI foi um período de desenvolvimento cultural: a queda de Constantinopla fezcom que estudiosos que ali viviam fossem atuar em outros locais; a descoberta do Novo Mundo estimulou seu estudo e o desenvolvimento náutico; a invenção da imprensa possibilitou a divulgação dos conhecimentos (Leicester, 1956).

Paralelamente às antigas práticas alquímicas, desenvolveram-se técnicas de manipulação da matéria para fins utilitários: preparação e medicamentos, análise de minérios, metalurgia. O desenvolvimento técnico, porém, não foi acompanhado do teórico (Leicester, 1956). Ainda não havia o conceito de ácido, mas, de material ácido, como material de sabor azedo. Tais materiais em si e seus usos não constituíam problemas que requeressem a criação desse conceito. A transformação do adjetivo ácido em substantivo e classe de materiais se deu à medida que o sabor azedo passou a caracterizar uma quantidade maior de materiais e que seu emprego na medicina se tornou importante.

\section{Conceitos de Ácido e de Álcali Caracterizados Empiricamente}

Os conceitos de ácido e base/álcali se desenvolveram em fases. A primeira fase compreende o século XVII e o século XVIII, até cerca de 1770, quando Lavoisier iniciou a publicação dos seus trabalhos acerca do assunto.

No século XVI, os conhecimentos alquímicos foram associados à medicina. Um expoente dessa articulação foi Paracelso (Philippus Aureolus Thophrastus Bombastus von Hohenheim), que desenvolveu um conjunto singular de ideias acerca do mundo e do funcionamento do corpo humano - conhecido como Iatroquímica - o qual tinha entre seus pressupostos a noção de que "as funções do organismo vivo eram principalmente determinadas por atividades químicas ('efervescências')" (Partington, 1961, p. 283-284). Paracelso também introduziu a tria prima: mercúrio, enxofre e sal, como um sistema de 
princípios que explicariam todos os materiais. Suas ideias influenciaram os estudos da matéria e da medicina no século seguinte.

A Iatroquímica contribuiu para o desenvolvimento do estudo dos materiais, sua obtenção e purificação, com finalidade médica. No século XVII desenvolveram-se ideias teóricas e estudos experimentais que conduziram à elaboração dos conceitos de ácido e álcali, a partir da necessidade do ser humano de ordenar o mundo material, caracterizando e classificando os materiais com os quais lidava, fossem extraídos da natureza ou produzidos artificialmente. A caracterização era realizada por aspectos empíricos (Crosland, 1978) próprios dos materiais e das suas relações com outros materiais. A composição química dos materiais só adquiriu relevância como uma característica identitária e classificatória no final do século XVIII.

Foi no século XVII que ocorreram os primeiros registros do substantivo ácido em línguas latinas (ácido, acide) e inglesa (acid) (Acid, 2019; Acide, 2013; Ácido, 2001). Embora o substantivo álcali tenha sido empregado em francês (alcali) e inglês (alkali) desde o século XIV (Alcali, 2013; Alkali, 2019), o primeiro registro de seu uso em língua portuguesa é do final do século XVII (Álcali, 2001).

Seguidor da Iatroquímica, Jean Baptiste van Helmont desenvolveu uma teoria dos processos vitais como vinculados a vários tipos de fermentos. Conhecedor de diversos materiais ácidos e alcalinos entendia haver mútua eliminação nas suas reações (Partington, 1961). Sua explicação da digestão dos seres vivos considerava que a primeira etapa se dava no estômago, por ação de um fermento digestivo ácido, seguida da passagem do material em digestão ao intestino, onde perdia a acidez por ação da bile, reconhecida como um material alcalino, "que mudava sua acidez em sal" (Debus, 2002, p. 371). Dessa descrição, pode-se inferir que a digestão envolvia uma reação de neutralização, sendo, assim, um embrião da ideia de que sais seriam formados por ácidos e álcalis. Embora o fermento ácido fosse necessário à digestão estomacal, um excesso podia causar "desconforto e doença” (Partington, 1961, p. 236). Também as feridas apresentavam uma acidez indicativa da putrefação da carne, a qual podia ser eliminada por álcalis (Debus, 2002).

No mesmo período, Glauber, químico, e Le Fréve, médico, também elaboraram a noção de que sais neutros seriam formados a partir de ácidos e álcalis e que estes se destruíam e anulavam mutuamente (Partington, 1961; 1962; Siegfried, 2002). As noções de oposição entre ácidos e álcalis por meio da neutralização e de complementaridade pela formação de sais estavam sendo construídas.

Sylvius, iatroquímico e professor, influenciado por Glauber e van Helmont, propôs que a digestão seria resultante da mistura da saliva (ácida), do suco pancreático (ácido) e da bile (alcalina) sobre o alimento. A competição entre ácido e álcali produzia efervescência, gás e calor. Similarmente, o calor corporal seria resultante da reação de porções sanguíneas ácidas e alcalinas no coração. Desse modo, Sylvius veio a supor que os distúrbios no corpo humano pudessem ser atribuídos a excessos ácidos ou alcalinos. A cura da doença ocorreria pela neutralização do excesso, empregando-se remédios ácidos 
ou alcalinos (Boas, 1956; Partington, 1961). Como professor em Leyden, influenciou uma grande quantidade de estudantes de várias nacionalidades, divulgando as ideias de oposição e complementaridade entre ácido e álcali, de efervescência e aquecimento durante sua reação (Debus, 2002; Partington, 1961).

Otto Tachenius, também iatroquímico, admitia a existência de um fermento universal, um sal da natureza, decorrente da união do fogo (ácido) com a água (álcali), ideias que atribuía a Hipócrates e Galeno. Com a publicação do Hipocrates Chemicus, em 1666, procurou demonstrar que todos os materiais apresentavam acidez ou alcalinidade e popularizou a teoria de Sylvius. De acordo com Tachenius, "todos os sais podem ser divididos em duas partes, em álcali e ácido" (Partington 1961, p. 293) e tanto ácidos quanto álcalis apresentavam forças diferentes, sendo que o material mais forte deslocaria o mais fraco do sal (Boas, 1956; Partington 1961).

As ideias de Sylvius e Tachenius acerca das reações entre ácidos e álcalis influenciaram médicos e químicos, como Nicolas Lémery, que adotou uma teoria atômica derivada de Descartes e Gassendi, concebendo as partículas materiais com tamanhos e forma distintas, dotadas de saliências ou orifícios: as partículas dos ácidos possuíam protuberâncias pontiagudas, conforme se podia constatar pela sensação de picada na língua ao se provar um ácido; as partículas dos álcalis, duras e quebradiças, possuíam poros. Quando os dois tipos de partículas se encontravam, as protuberâncias penetravam os poros. $\mathrm{O}$ acoplamento restringia os movimentos das partículas do ácido que, na tentativa de escapar, quebravam suas protuberâncias nas partículas do álcali. Tão forte rompimento produzia a efervescência da reação, que se completava quando todas as protuberâncias eram quebradas e todos os poros preenchidos (Boas, 1956; Partington, 1962). Por isso, a efervescência da reação era entendida como "manifestação de vigorosa 'luta', [...] resultante de reação violenta" (Siegfried, 2002, p. 76), de modo que seu término indicava o fim da reação, ou seja: a mútua anulação do ácido e do álcali, com produção do sal neutro (Siegfried, 2002).

Influenciado por Le Fréve, Lémery publicou em 1675, um livro-texto intitulado Cours de Chimie, que foi muito bem aceito, tendo tido várias edições e sido traduzido em latim, inglês, alemão, holandês, italiano e espanhol (Boas, 1956; Partington, 1962), divulgando amplamente sua teoria ácido-álcali.

Ácidos e álcalis passaram a ser amplamente considerados como princípios formadores dos materiais (Boas, 1956), o que tinha lógica: se o sal, a partir de Paracelso, era admitido como um princípio até então, o fato de ser composto por ácido e álcali implicava em que estes componentes seriam os verdadeiros princípios materiais.

Por outro lado, os antigos sistemas dos quatro elementos (ar, fogo, água e terra) e/ou dos três princípios (sal, enxofre e mercúrio) já se mostravam pouco eficazes na explicação do mundo (Boas, 1956). Conforme escreveria Lavoisier (2007) cerca de cem anos depois: "Uma coisa muito notável é que, ensinando a doutrina dos quatro elementos, não há químico que, pela força dos fatos, não tenha sido levado a admitir um número ainda maior" (p. 20). 
Em 1692, Isaac Newton, também numa abordagem corpuscular, propôs que os ácidos fossem constituídos por partículas que teriam grande força atrativa por corpos de natureza terrestre e aquosa. Álcalis seriam compostos por uma junção de terras e ácidos. Newton considerava que os ácidos estavam envolvidos em todas as dissoluções, fosse de modo aparente ou latente. Por exemplo: na dissolução de um metal, "as partículas do solvente envolvem as do metal, rasgam-nas em pedaços e dissolvem-nas”. Também estariam envolvidos em todas as fermentações: ao moverem-se, as "partículas do ácido movimentam o fluido e suscitam calor, agitam separando algumas partículas, jogamnas ao ar e geram bolhas [...]" (Newton citado por Partington, 1961, p. 482).

Portanto, os estudos dos materiais no século XVII conduziram paulatinamente para que outros traços viessem se somar ao sabor - critério que permaneceu até o século XVIII (Crosland, 1978) - na caracterização dos ácidos e álcalis:

a) Ácidos e álcalis eram princípios materiais;

b) Ácidos e álcalis formavam sais, se complementando;

c) Ácidos e álcalis se anulavam por reação, estabelecendo-se como opostos;

d) A reação entre ácido e álcali produzia efervescência, calor e agitação, o que servia como critério para sua identificação: se um material reagisse com ácido e produzisse efervescência seria um álcali e vice-versa;

e) Ácidos eram bons solventes.

A atribuição de mais características aos conceitos de ácido e álcali fez com que aumentasse a especificidade dos mesmos, contribuindo para diferentes compreensões e explicações de objetos, situações e eventos. O amplo conceito baseado no sabor do material havia se prestado apenas para uma primeira classificação.

É importante notar que tais características não eram conjuntamente empregadas pelos usuários desses compostos. O conhecimento estava geograficamente disperso porque a comunicação entre os estudiosos era difícil e não havia consenso acerca das propriedades dos ácidos e álcalis.

Por outro lado, essas ideias não ficaram isentas de críticas. Herman Boerhaave, importante médico do período, refutou a teoria fisiológica ácido-álcali por não conseguir comprová-la experimentalmente. Utilizou o critério de efervescência durante a reação, mas não conseguiu caracterizar a natureza ácida ou alcalina de vários fluidos animais, tais como: saliva, suco estomacal, suco pancreático, bile, urina, leite, clara de ovo. Suas experiências nem sempre eram bem conduzidas, como no caso do suco estomacal que concluiu ser neutro (Jevons, 1962).

Outro crítico importante do período foi Robert Boyle. Em um ensaio intitulado "Reflexões sobre a hipótese de álcali e ácido", Boyle (1675) questionou a conceituação desses materiais e seu caráter elementar. Em dado trecho, afirmava: "Não me espanto que as definições que nos dão de ácidos e álcalis sejam inexatas e superficiais, pois não encontro, que os próprios químicos tenham qualquer noção clara e determinada, ou 
traços seguros, por meio dos quais saber distingui-los" (p. 14). Na sequência apontava várias inconsistências dos critérios de caracterização de ácidos e álcalis - o sabor, a dissolução de materiais, os efeitos de reação citados acima - dado que todos apresentavam exceções. Em outros estudos a respeito das cores, Boyle (Boyle, 1664; Brock, 2000; Ihde, 1984) já havia verificado que ácidos e álcalis produziam diferentes mudanças de cor em várias soluções de origem vegetal, o que poderia constituir testes para a sua identificação e critérios de conceituação mais precisos. Estudos sistemáticos conduziram aos atuais indicadores ácido-base (Baker Jr., 1964).

Conforme assinala Goldfarb (2005), as críticas de Boyle não repercutiram entre outros estudiosos da matéria, tanto que, cem anos depois, o sabor azedo e a efervescência em reações comálcalis eram ainda citadas como características dos ácidos na Enciclopédia de Diderot e D’Alembert (Acide, 1751-1765). Apenas as mudanças de cor provocadas pelos ácidos em outros materiais foram consideradas. Na mesma Enciclopédia, álcalis eram considerados como materiais que produziam efeitos contrários aos dos ácidos (Alkali, 1751-1765).

No século XVIII se intensificaram os estudos acerca dos materiais visando caracterizá-los e explicar suas reações. Em 1718, Geoffroy publicou suas primeiras tabelas de afinidade, nas quais empregava o termo ácido (acide) como substantivo indicativo de classe de substâncias (Geoffroy, 1741): o conhecimento químico adquiria maior sistematização.

O termo base havia sido inserido na Química por Louis Lémery, filho de Nicolas Lémery, nas primeiras décadas do século XVIII, relacionado ao conceito iatroquímico de matriz, que remetia à origem dos materiais (Siegfried, 2002; Jensen, 2006). Em 1744, Rouelle empregou o termo base para significar os diversos tipos de substâncias que reagiam com os ácidos para formar sais neutros: álcalis, terras absorventes, metais e óleos (Rouelle, 1748). Dez anos depois, em uma continuação do trabalho anterior, Rouelle (1759) redefiniu sal como "formado pela união de um ácido com uma substância qualquer que lhe serve de base" (p.573-574), empregando o termo base como classe de substâncias.

Então, no terceiro quartel do século XVIII, base de um composto era definida como "todo corpo que se considera como dissolvido por outro corpo que ele recebe, que ele fixa e com o qual ele constitui esse composto". Exemplos de "bases de sais neutros" seriam "as substâncias alcalinas, terrosas e metálicas, que dissolvidas até a saturação pelos diferentes ácidos, formam os sais neutros por união com esses mesmos ácidos" (Macquer, 1778, p. 237).

Na sua formulação, o conceito de base constituiu-se como mais geral do que álcali, que se tornou um de seus tipos particulares. A diversidade dos materiais que serviam de base para a formação de sais impossibilitava que tivessem características específicas comuns. O ganho em generalidade implicou em perda da capacidade de discriminação do conceito, pois o fato de um material neutralizar ácidos não indicava que fosse álcali, terra, metal ou óleo. 
Ácidos, por seu turno, ainda eram principalmente caracterizados por: sabor azedo; alteração da cor de extratos vegetais, reação com bases produzindo sais (Macquer, 1756; 1778; Acide, 1751-1765).

Tanto ácidos quanto bases eram reconhecidos como igualmente ativos durante o processo, pois "em toda combinação e dissolução, os corpos que se unem são igualmente ativos, sua ação é recíproca: eles se dissolvem um ao outro” (Macquer, 1778, p. 237). Desse modo, a oposição (neutralização) e a complementaridade (formação de sal) entre ácido e álcali foram transferidas para ácido e base.

Convém salientar que até então, os critérios empregados para conceituar ácido e/ ou base eram majoritariamente empíricos, advindos dos ensaios laboratoriais e da prática médica, constituindo-se em características próprias das substâncias (sabor) ou de seu comportamento frente a outros materiais (poder solvente, efervescência). Os trabalhos de Lavoisier viriam a introduzir a composição química como critério de acidez.

\section{Conceitos de Ácido e de Álcali/Base Caracterizados por Composição Química}

Embora Lavoisier tenha sido o primeiro a propor um conceito de ácido fundamentado na composição química, seu conceito se deveu muito a outros estudiosos da segunda metade do século XVII e do século XVIII. Nesse período, foram criadas as teorias do flogístico, das afinidades e do calórico, assim como novas concepções acerca da combustão; desenvolveram-se os estudos que levaram ao reconhecimento da multiplicidade dos ares (gases), das terras e das águas, estabelecendo um novo entendimento de elemento como ponto final da análise; a composição elementar foi proposta como critério de identidade química, o que viria a produzir uma sistematização dos conhecimentos químicos sem precedentes (Leicester, 1956; Ihde, 1984).

Em seus trabalhos acerca de ácidos, Lavoisier foi especificamente influenciado por: (a) discussões acerca da natureza ácida universal do ar fixo ou acido aëreo (atual dióxido de carbono); (b) noção de causticidade, relacionada ao ácido universal e ao ar fixo; (c) crescente descoberta de novos ácidos, tanto orgânicos quanto inorgânicos; (d) conhecimento de que reações de combustão produziam ácidos. No período de $1772-$ 1780, Lavoisier desenvolveu estudos acerca do princípio acidificante que resultaram na sua teoria da acidez pelo oxigênio (Crosland, 1973; Le Grand, 1972).

As combustões eram reações de um material com o ar. Ciente dos estudos de Scheele acerca do ar empireal, e de Pristley, acerca do ar deflogistificado (ambos correspondendo ao atual oxigênio), Lavoisier realizou outras experiências, nas quais analisou o ar atmosférico e obteve duas partes consideradas simples: ar respirável e ar não respirável (Lavoisier, 2007).

As experiências de combustão do fósforo, do enxofre, do carvão com ar respirável produziam ácidos, os quais apresentavam aumento de massa em relação aos reagentes. Lavoisier interpretou os aumentos de massa e a formação dos ácidos como decorrentes da fixação do ar respirável pelas bases acidificáveis (fósforo, enxofre e carvão), ou seja: 
explicava a acidez da substância obtida pela presença do ar respirável fixado (incluído) em sua composição, em lugar da presença de um ácido universal. É conveniente lembrar que os ácidos estudados por Lavoisier consistiam nos atuais anidridos inorgânicos, a exemplo de óxidos de fósforo, de enxofre e carbono (Crosland, 1973; Le Grand, 1972).

Na concepção de Lavoisier (2007), todas as substâncias estavam combinadas com o calórico, considerado como um elemento que tudo penetrava. O estado gasoso de uma substância se devia a uma combinação de uma base (uma substância) com uma grande quantidade de calórico. Uma evidência seria o fato de que a passagem de uma substância do estado líquido ou sólido para gás requeria aquecimento, durante o qual aumentava a quantidade de calórico combinado com a substância que servia de base para o gás. A base do ar respirável foi denominada oxigênio e a base do ar não respirável, azoto (atual nitrogênio). O gás oxigênio - ar respirável - seria uma combinação de oxigênio com calórico. Analogamente, o gás azoto seria a combinação de azoto com calórico.

A formação dos ácidos se devia à maior afinidade do oxigênio pela base acidificável, levando o gás oxigênio a se decompor e liberar o calórico, o que explicava os efeitos térmicos das reações de combustão. A generalização desses resultados levou à proposição de que a formação de todos os ácidos se dava pela combinação do oxigênio com uma base acidificável:

Vê-se que o oxigênio é o princípio comum a todos [os ácidos] e ele constitui a sua acidez; e que [os ácidos] são diferenciados uns dos outros pela natureza da substância acidificada. Portanto, é preciso distinguir, em todo ácido, a base acidificável, [...] e o princípio acidificante, isto é, o oxigênio (Lavoisier, 2007, p. 57).

$\mathrm{O}$ oxigênio, como princípio acidificante, apresentava maior concretude do que o flogístico ou o ácido universal, pois podia ser identificado e obtido na forma do gás oxigênio (Crosland, 1973; Le Grand, 1972), fato que conferia maior credibilidade ao conceito.

A teoria dos ácidos de Lavoisier (2007) estava relacionada com sua concepção de elemento químico ou substância simples, definido como "o último termo a que chega a análise", ou seja: "as substâncias que ainda não pudemos decompor por algum meio" (p. 21). Portanto, a elementaridade ou simplicidade de uma substância estava determinada pelos métodos de análise disponíveis. Na Tabela das Substâncias Simples (p. 116) do Tratado, o oxigênio é apresentado como uma substância simples.

O novo conceito de ácido representou uma mudança substancial em relação ao anterior, pois era caracterizado pela composição em vez de pelo comportamento frente a outras substâncias. Lavoisier não se propôs a resolver os problemas levantados pelas críticas de Boerhaave, Boyle ou outro estudioso, mas a elaborar um conceito que explicasse a formação dos ácidos na combustão.

A teoria possibilitava previsões: se todo ácido deveria ser um composto de oxigênio com uma base acidificável (também denominada radical de ácido), então, a cada ácido cuja composição não era ainda conhecida, deveria haver uma base acidificável correspondente. Na Tabela das Substâncias Simples do Tratado (Lavoisier, 2007), 
constam três bases consideradas desconhecidas: "radical muriático", "radical fluórico" e "radical borácico" (p. 116).

O termo base foi bastante utilizado no Tratado com o sentido geral de substância que se combinava com outra. Apenas no caso da formação dos sais neutros, as bases salificáveis adquiriam o significado atribuído por Rouelle, de substância que reagia com ácido para formar sal neutro, ou seja: como substância que neutralizava ácido. As bases salificáveis eram: os álcalis (potassa, soda, amoníaco), terras (cal, magnésia, barita, alumina) e metais (foram citados 17 metais).

A existência de um princípio acidificante levou, por analogia, à pressuposição de um princípio alcalinizante, os quais se neutralizariam quando da formação de um sal neutro. Hidrogênio e nitrogênio foram sugeridos como tal princípio, uma vez que ambos haviam sido detectados no amoníaco. Objeções foram levantadas - nitrogênio formava ácidos - e não se conseguiu realizar experiências conclusivas a respeito do hidrogênio (Le Grand, 1974).

O conceito de ácido como composto oxigenado repercutiu fortemente entre os químicos (Le Grand, 1974), entretanto, críticas foram se acumulando durante o trabalho de Lavoisier e nos anos seguintes. Scheele havia descoberto, em 1777, que o ar sulfuroso $\left(\mathrm{H}_{2} \mathrm{~S}\right)$ não continha oxigênio, embora apresentasse propriedades ácidas (Ihde, 1984). Berthollet também teve dúvidas, pois suas análises do ácido prússico (HCN), em 1787, não haviam identificado a presença de oxigênio e, no período 1789-1796, ele identificou que os ácidos muriático, fluórico, borácico, úrico e o hidrogênio sulfurado não apresentavam oxigênio em sua composição (Bardez, 2012).

A invenção da pilha eletroquímica possibilitou que a soda e a potassa fossem eletroliticamente decompostas por Davy, em 1807, produzindo oxigênio e dois novos elementos, denominados sódio e potássio. Tal fato pôs em questão a noção de oxigênio como princípio acidificante, uma vez que os compostos analisados eram álcalis (Bardez, 2012).

Dois anos depois, tentou-se decompor o radical do ácido muriático por vários métodos químicos, sem sucesso, chegando à suposição de que "esse gás é um corpo simples" (Gay-Lussac; Thenard, 1809, p. 358). Uma vez que nem o ácido muriático nem seu radical se decompunham em oxigênio, levantava-se a dúvida sobre a proposição desse elemento como princípio acidificante (Bardez, 2012).

As subsequentes descobertas do flúor, do iodo e do bromo e a ausência de oxigênio na composição dos ácidos correspondentes vieram se juntar aos elementos contrários à teoria ácida do oxigênio (Bardez, 2012; Ihde, 1984).

Liebig (1840) admitia a existência de ácidos contendo oxigênio ou não. Nos anos 1860, o grupo $\mathrm{COOH}$, denominado posteriormente como carboxila por Butlerov, foi reconhecido como sendo característico dos ácidos orgânicos (Partington, 1964), ou seja: tanto oxigênio quanto hidrogênio eram seusconstituintes.

Foram criadas as denominações oxiácido e hidrácido para ácidos contendo oxigênio e hidrogênio, respectivamente (Partington, 1964): já não se podia falar de um 
princípio acidificante sem incorrer em controvérsia.

Cabe notar uma mudança conceitual importante ocorrida nas primeiras décadas do século XIX: a fixação do conceito de base como substância neutralizadora de ácido. Introduzido nas discussões sobre ácidos e bases, em 1754, o termo base ainda não tinha fixado seu significado específico no Tratado de Lavoisier, publicado em 1789. Porém, foi claramente empregado nesse sentido por Liebig e Berzelius em correspondência trocada em 1831 (Carrièrre, 1893) assim como no Tratado de Química Orgânica de Liebig (1840).

\section{Conceitos de Ácido e de Base Caracterizados por Composição Química e Reações de Dissociação e/ou Associação}

Em 1800, foi inventada a pilha elétrica e logo se seguiram os estudos de decomposição eletroquímica dos materiais. Pouco tempo depois, Dalton lançou sua teoria atômica. As decomposições eletrolíticas receberam diferentes interpretações, sendo as mais importantes propostas por Gröthuss, Davy, De La Rive, Berzelius, Roget, Daniell e Faraday. Este criou os termos que empregamos até hoje nos sistemas eletroquímicos: eletrodos, cátodo, ânodo, eletrólito. Íons seriam as partes nas quais as moléculas se decompunham, sendo denominadas cátions e ânions, por se dirigir ao cátodo e ao ânodo, respectivamente. Faraday propôs haver uma quantidade de eletricidade associada a cada átomo (Whittaker, 1910).

A explicação da decomposição eletroquímica de uma substância supunha que, por ação da força elétrica aplicada, inicialmente ocorria sua dissociação em íons, os quais se moviam em direção aos eletrodos. A dissociação requereria algum consumo de eletricidade, fato que não era observado experimentalmente. Então, na segunda metade do século XIX, Williamson sugeriu que a dissociação e a associação das moléculas em íons ocorriam continuamente em solução sem intervenção externa. Clausius desenvolveu a proposta sugerindo que os íons eram eletricamente distintos e que a eletrólise ocorria quando a força elétrica aplicada provocava o movimento dos diferentes íons em direção aos correspondentes eletrodos. A teoria dos movimentos iônicos em solução foi desenvolvida por Hittorf e Kohlrausch (Whittaker, 1910).

Apoiado nas ideias de Williamson, Clausius e Kohlrausch, em junho de 1883, Svante Arrhenius defendeu tese de doutorado, na qual propôs sua Teoria da Dissociação Eletrolítica (Arrhenius, 1884). Em meio à explicação do calor de neutralização ácidobase por tal teoria, considerou que essa reação consistia na "[...] transformação de uma base e de um ácido perfeitamente ativos [dissociados (Arrhenius, 1887a; 1887b)] em água e um sal [...]", sendo que a água "se forma pela colisão de dois íons $\mathrm{H}$ e $\mathrm{OH}$ dotados de movimento" (Arrhenius, 1884, 1'Parte, p. 72).

Nesse período, havia controvérsias acerca da teoria atômica e a aceitação consensual da dissociação eletrolítica ainda levaria alguns anos para acontecer. Por isso, embora o termo íon seja empregado na tese, as expressões dominantes são parte ativa ou molécula ativa: "A solução aquosa de um hidrato qualquer se compõe, exceto a água, de 
duas partes, uma ativa (eletrolítica), e outra inativa (não eletrolítica)" (Arrhenius, 1884, 2a Parte, p. 5). É notável que, na tese, Arrhenius (1884) não tenha apresentado uma única equação química sequer correspondente a processo de dissociação eletrolítica.

Três anos depois, Arrhenius (1887a; 1887b) buscou dar consistência ao conceito de dissociação molecular - entendida como divisão de uma molécula em átomos - e, então, os termos íon e parte ativa foram usados igualmente. Além disso, foram apresentadas equações químicas relativas à reação de neutralização ácido-base, a exemplo de:

$$
(\mathrm{NaOH})+(\mathrm{HCl})=\left(\mathrm{H}_{2} \mathrm{O}\right)-[\mathrm{Na}]-[\mathrm{Cl}],
$$

na qual os parênteses indicam moléculas neutras e os colchetes indicam íons. A grafia desta equação com a indicação das cargas dos íons só viria a acontecer no Textbook of Electrochemistry (Arrhenius, 1902), escrito com base nas notas de aula de 1987 e na Conferência Nobel (Arrhenius, 1903).

Arrhenius $(1884 ; 1903)$ partiu do princípio de que todo ácido é um eletrólito que se dissocia em água, considerando que um ácido eletroquimicamente ativo é quimicamente ativo. De acordo com essa teoria, ácidos e bases fortes, assim como sais, quando em extrema diluição, encontram-se quase completamente dissociados em seus íons. Por outro lado, a água era considerada como dificilmente dissociável em íons.

No final do século XIX, a noção de átomo estava fortalecida na Química, principalmente pelo desenvolvimento da Química Orgânica, de modo que, juntamente com a descoberta do elétron, gerou o conceito moderno de íon como átomo carregado de eletricidade. Então, a reação de neutralização de um ácido forte com uma base forte diluídos podia ser expressa, por exemplo, do seguinte modo:

$$
\mathrm{H}^{+}+\mathrm{Cl}^{-}+\mathrm{Na}^{+}+\mathrm{OH}^{-}=\mathrm{Na}^{+}+\mathrm{Cl}^{-}+\mathrm{HOH} \text {. }
$$

Como o sal permanecia dissociado, a reação que efetivamente ocorria era: $\mathrm{H}^{+}+\mathrm{OH}^{-}=$ $\mathrm{HOH}$, a qual independia da natureza do ácido forte e a base forte. Em suma: "Quando ácidos fortes e bases fortes reagem, água é formada, e o calor que é liberado é, simplesmente, o calor de formação de água inativa [não dissociada] a partir de água verdadeiramente ativa [dissociada]" (Arrhenius, 1912, p. 359).

Nota-se que Arrhenius não tinha os conceitos de ácido e base como problemas, mas que argumentava em favor da validade da teoria que havia desenvolvido, com a qual tinha a pretensão de explicar a condutividade de soluções de ácidos e bases e o calor de neutralização. Mesmo assim, contribuiu para dar apoio à noção de ácido como composto de hidrogênio.

Nos seus trabalhos da época, Arrhenius (1884, 1887a, 1902, 1903, 1912) não chamou a atenção para as definições de ácidos e bases. Contudo, Richard Abegg, colaborador de Arrhenius, publicou, em 1903, o livro intitulado The Electrolitic Dissociation Theory (Abegg, 1907), no qual apresentou as seguintes definições:

[...] era suficientemente bem conhecido que seus [dos ácidos e das bases] constituintes característicos eram $\mathrm{H}$ e $\mathrm{OH}$, respectivamente, apesar de que não tivesse sido possível definir sob que circunstâncias esses componentes mostravam propriedades ácidas ou 
básicas, pois há numerosos compostos contendo $\mathrm{H}$ ou $\mathrm{OH}$ que não são necessariamente ácidos ou bases. A teoria da dissociação, no entanto, nos define essas substâncias tais como aquelas que contêm $\mathrm{H}$ ou $\mathrm{OH}$ na forma de íons como resultados da dissociação eletrolítica e torna claro de uma vez o modo de nos informar em relação ao grau das propriedades ácidas e básicas de um composto, pela determinação da concentração desses íons H’ ou OH’ característicos (Abegg, 1907, p. 5).

Desse modo, os conceitos de ácido e base foram modificados, tornando-se mais específicos: em termos de composição elementar, as características dos ácidos se restringiam ao elemento hidrogênio; além disso, o hidrogênio deveria ser ionizável em água. As bases se limitavam a compostos contendo hidroxilas, que também deveriam ser ionizáveis em água. Ou seja: ao critério composicional foi adicionado um critério comportamental. Foi mantida a característica de ácido e base se neutralizarem mutuamente, formando sais.

Os conceitos de ácido e base de Arrhenius se mostraram limitados para conhecimentos químicos da época, por exemplo, as dificuldades em explicar: (a) a neutralização de ácidos por compostos que não produziam ânions $\mathrm{OH}^{-}$, a exemplo das aminas; (b) reações com características ácido-base em fase gasosa e em solventes não aquosos não ionizáveis, como benzeno; (c) evidências de que o íon hidrogênio em solução deveria estar solvatado (Bell, 1947; Jensen, 2016a). Tais limitações conduziram a outras conceituações de ácido e base.

Edward Franklin $(1905,1912)$ traçou um paralelismo entre os conceitos de ácido, base e sal em meio aquoso e em meio amoniacal, depois expandido para outros solventes. Considerou ácidos, bases e sais como derivados de um solvente matriz, a partir do qual eram definidos (Franklin, 1924). Na esteira dos trabalhos de Franklin e outros, Germann estabeleceu as seguintes definições:

Um solvente matriz é uma substância a partir da qual um sistema de solvo ácidos, solvo bases e solvo sais é derivado.

Um solvo ácido é qualquer eletrólito que, em dado solvente, produz cátions idênticos aos cátions do solvente matriz e ânions que contêm átomos característicos do solvo ácido particular juntamente com átomos característicos do ânion do solvente matriz.

Uma solvo base é qualquer eletrólito que, em dado solvente, produz cátions metálicos simples e ânions idênticos aos ânions do solvente matriz.

Um solvo sal é o eletrólito produzido quando um solvo ácido reage com um metalou uma solvo base derivada do mesmo solvente matriz (Germann, 1925, p. 2464).

A neutralização era entendida como a reação de um solvo ácido com uma solvo base ou com um metal. No primeiro caso, era produzindo um solvo sal e o solvente matriz; no segundo, os produtos eram um solvo sal e o cátion do solvente matriz (Germann, 1925).

Solvo ácidos e solvo bases expandiram os conceitos de ácido e base formulados por Arrhenius para solventes diferentes da água em função de suas características de se 
dissociarem eletroliticamente em soluções do solvente matriz. O critério da composição se ampliou ao incluir outros cátions e ânions diferentes do $\mathrm{H}^{+} \mathrm{e} \mathrm{OH}^{-}$, respectivamente.

Em 1907, Werner ampliou o conceito de base de Arrhenius. O problema que levou Werner à formulação desse conceito foi a descoberta, por Pfeiffer, de que complexos de crômio formavam sais ao reagir com ácidos. Então, Werner verificou que o mesmo ocorria com complexos de cobalto, rutênio e platina (Kauffman, 1973; Werner, 1911). A lógica que supomos haver presidido o raciocínio de Werner foi que, se os sais são formados por reações entre ácidos e bases, os complexos metálicos deveriam ser bases.

Ao estudar os hidroxo complexos de cobalto amina, Werner (1913) constatou que, a depender da natureza dos átomos centrais (centros metálicos) e dos outros grupos ligados (ligantes: $\mathrm{NH}_{3}$ etc.), os grupos hidroxila ligados ao átomo de metal teriam uma menor ou maior tendência de se ligar aos íons de hidrogênio presentes na água. Quanto maior fosse essa tendência, mais fortemente básicos seriam esses hidroxo compostos. Então, definiu bases como "todos os compostos de adição com água que formam íons hidroxila em soluções aquosas" (Werner, 1911, p. 205). Em outras palavras,

bases são compostos que têm a capacidade de se ligar aos íons hidrogênio da água, e desta forma, perturbar o equilíbrio entre a água e os seus íons por absorção de íons hidrogênio, o que resulta em um aumento da concentração de íon hidroxila (Werner, 1913, pp. 262-263).

Ácido seria "todo composto de adição formado com água que, em solução aquosa, dissocia em hydrion [íon hidrogênio associado com molécula de água]" (Werner, 1911, p. 205).

No início do século XX, se desenvolveram estudos acerca da estrutura da matéria a partir da descoberta do elétron e do núcleo atômico, dos quais derivaram modelos para o átomo. Paralelamente, foram sugeridos modelos para as ligações químicas (Lopes, 2009). Em 1921, Michaelis analisou o comportamento de íons $\mathrm{H}^{+}$e $\mathrm{OH}^{-}$em soluções aquosas apoiado no modelo atômico de Bohr: as pequenas dimensões dos íons $\mathrm{H}^{+}$ faziam com que fossem mais fortemente ligados a íons de carga oposta ou a moléculas; o mesmo não ocorria com os íons $\mathrm{OH}^{-}$, que são maiores. Para explicar o comportamento básico de substâncias tão diversas como $\mathrm{NaOH}$ e $\mathrm{NH}_{3}$, ele propôs definir base como substância neutra que se dissocia em íons $\mathrm{OH}^{-}$ou se associa a íons $\mathrm{H}^{+}$. Para atender ao critério de que ácidos e bases deveriam se neutralizar, ácido deve ser substância neutra que se dissocia em íons $\mathrm{H}^{+}$ou se associa a íons $\mathrm{OH}^{-}$(Michaelis, 1926). Esses conceitos resolviam algumas das limitações dos conceitos de ácido e base de Arrhenius: incluíam compostos não hidroxilados na classe das bases (a exemplo da amônia) e compostos não hidrogenados na classe dos ácidos (como o dióxido de carbono); explicavam a solvatação dos íons hidrogênio em solução e ampliavam os conceitos de ácido e base de Werner (que Michaelis, possivelmente, não conhecia, já que não os citou, embora tenha mencionado o "número de coordenação de Werner" em seu livro (p. 126)).

As definições de Werner e Michaelis se limitaram às soluções aquosas, porém, ampliaram os conceitos de Arrhenius, e foram precursoras daquelas que viriam a ser 
desenvolvidas dezesseis anos depois, por Brönsted e Lowry.

Lowry estava a par e participava dos desenvolvimentos da teoria atômicomolecular, compondo a Escola Inglesa da Química Orgânica, que adotava a concepção do par eletrônico de valência (Brock, 2000; Jensen, 2016b). Foi no contexto de discussões acerca das ligações químicas em compostos que Lowry (1923a) propôs, em janeiro de 1923, uma nova concepção de base como "aceptor de núcleos de hidrogênio" (p. 47). Seu argumento adotava como premissas que: (a) ácidos eram compostos que se dissociavam liberando íon hidrogênio; (b) o átomo de hidrogênio podia, de acordo com a teoria do octeto, realizar ligações por covalência ou eletrovalência; (c) tal fato explicava a existência de ácidos nas formas de compostos dissociados (eletrovalentes) e não dissociados (covalentes); (d) íons hidrogênio tendem a se ligar aos octetos de outros átomos, e não a permanecerem como núcleos atômicos isolados em meio a outros átomos. Então concluiu:

É comumente sugerido que os álcalis ou bases são tão únicos quanto os ácidos e que o íon hidroxila ocupa uma posição peculiar tanto quanto o íon hidrogênio. Isto, entretanto, é uma visão limitada, baseada no fato de que a maioria do nosso trabalho químico é realizado em presença de água, senão em soluções aquosas, realmente. A verdadeira função de uma base é a de um aceptor de núcleos de hidrogênio [...] (Lowry, 1923a, p. 46).

Portanto uma molécula de água poderia servir de aceptor de íons hidrogênio, de modo que a ionização de um ácido fosse um processo de transferência de próton do ácido não dissociado para a água.

Em 13-14 de julho de 1923, Lowry coorganizou uma conferência para a Faraday Society sobre "A Teoria Eletrônica de Valência" (Brock, 2000), durante a qual se convenceu de que o próton dissociado não deveria permanecer isolado, mas, estar sempre ligado a outro átomo, o que fortaleceu sua concepção de base como aceptor de prótons. Desse modo, a ionização de um ácido, a exemplo do $\mathrm{HCl}$, deveria ser escrita como (Lowry, 1923b):

$$
\mathrm{HCl}+\mathrm{H}_{2} \mathrm{O}=\mathrm{H}_{3} \mathrm{O}^{+}+\mathrm{Cl}^{-} \text {. }
$$

Em novembro do mesmo ano, Lowry (1923b) procurou fortalecer sua justificativa para o novo conceito de base que havia proposto. Traçando uma analogia entre o papel de um aceptor de prótons (água) na ionização de um ácido e um aceptor de prótons (amônia) na progressiva ionização de complexos de cobalto com amônia e cloro, vinculou sua concepção de base às ideias de Werner. Entretanto, a definição de base de Werner se limitava a meio aquoso. Lowry encontrou na definição de base de Lewis a ampliação do conceito para meios não aquosos: "Uma substância básica é aquela que possui um par de elétrons solitário que pode ser usado para completar o grupo estável [de elétrons] de outro átomo" (Lewis citado por Lowry, 1923b, p. 1051).

Desse modo, a reação de neutralização podia ser entendida como o processo do próton completar seu grupo estável de elétrons por meio da associação com um par eletrônico não compartilhado (solitário) de outro átomo. Em suma: uma base seria um aceptor de prótons pelo fato de possuir um par de elétrons não compartilhado. 
Os casos nos quais bases liberam íons hidroxila são aqueles nos quais a água age como ácido, dissociando-se em íons hidrogênio e hidroxila. Estes, por sua vez, podem agir como bases, sendo aceptores de íons hidrogênio. Tal situação ocorre em meio aquoso. Contudo, o conceito de base como composto aceptor de íons hidrogênio é mais amplo, podendo ser utilizado em qualquer solvente no qual íons hidrogênio possam ser produzidos e, mesmo, em meio gasoso.

Lowry não concordava com a definição de ácido de Lewis - "uma substância ácida é aquela que pode empregar um par de elétrons solitário de outra molécula para completar o grupo [de elétrons] estável de seus átomos" (Lewis citado por Lowry, 1923b, p. 1051) - pois a mesma não estava de acordo com a característica de produzir prótons por dissociação. Seu conceito de ácido como composto que libera íons hidrogênio ainda se prende à noção de composição, porém, é mais amplo do que o conceito de Arrhenius e Werner no que se refere ao meio onde se dá essa liberação.

Em agosto do mesmo ano, Brönsted (1923) entrou na discussão. Considerou as definições de Arrhenius como limitadas e reconheceu os conceitos de Pfeiffer e Michaelis como avanços (não citou Lowry), porém, vinculados ao meio aquoso. Segundo ele, os conceitos de ácido e base deveriam independer de qualquer solvente, e propôs as seguintes definições: "ácidos e bases são substâncias capazes de liberar ou absorver íons hidrogênio, respectivamente" (p. 719), o que foi expresso quimicamente (em termos contemporâneos) como um equilíbrio ácido-base simples:

$$
\mathrm{A}(\text { ácido })=\mathrm{B} \text { (base) }+\mathrm{H}^{+} \text {. }
$$

A composição de dois sistemas simples produz um sistema ácido-base e um equilíbrio ácido-base duplo, que pode ser expresso por:

$$
\mathrm{A} 1+\mathrm{B} 2=\mathrm{A} 2+\mathrm{B} 1 .
$$

Esse equilíbrio poderia representar diversas reações importantes como neutralização, hidrólise, reações com indicadores, entre outros. Brönsted foi o primeiro cientista a introduzir o conceito de par ácido-base.

Convém salientar que segundo esse químico, o íon hidroxila, em princípio, não possuía uma posição de portador de propriedades básicas e não existia uma medida lógica para uma comparação das forças dos ácidos com as das bases.

Buscando solucionar problemas diferentes, os conceitos de base de Brönsted e de Lowry, resultaram mais gerais do que o de Arrhenius por serem aplicáveis a qualquer solvente e não terem vínculo com a composição da substância. Os conceitos de ácido ainda estavam presos à composição e sua maior generalidade se devia à validade em água e solventes não aquosos.

Em 1939, Hermann Lux (1939) propôs conceitos de ácido e base para óxidos em sistemas de alta temperatura, nas quais a dissociação de óxido ocorria de modo similar ao esquema proposto por Brönsted:

$$
\mathrm{B}=\mathrm{A}+\mathrm{O}^{2-} \text {. }
$$

Os conceitos foram desenvolvidos por Flood (1947), porém, mantiveram limitações em razão da especificidade dos sistemas aos quais se aplicavam. Este modelo 
guarda similaridade com aquele de Brönsted - um tipo de substância se transforma em outro por meio da transferência de um íon - embora os papéis de ácido e base estejam invertidos. Por isso, quando um ácido reage com uma base, vale também o modelo

$$
\mathrm{B} 1+\mathrm{A} 2=\mathrm{B} 2+\mathrm{A} 1 \text {. }
$$

Assim, o modelo de Brönsted foi ampliado no sentido de que a transferência de outros íons (cátions ou ânions) fosse utilizada na definição de ácidos e bases. Estava criado o modelo ácido-base ionotrópico (Gutmann, 1968).

Usanovich tornou os conceitos de ácido e base ainda mais gerais ao propor "um ácido como toda substância capaz de doar cátions ou de combinar com ânions e uma base como toda substância capaz de doar ânions ou de combinar com cátions", (Luder, 1940, p. 552) entendendo as reações de óxido-redução como casos particulares de reações ácido-base. Por definição, toda reação ácido-base tem sal como produto, o que é equivalente à neutralização. Esses conceitos são por demais abrangentes para serem de uso prático na discriminação de materiais.

\section{Conceitos de Ácido e de Base Caracterizados por Estrutura Atômico- Molecular e Reações de Adição}

Gilbert Lewis foi um químico norte-americano que, juntamente com Irving Langmuir, contribuiu decisivamente para a compreensão da ligação química em termos eletrônicos (tanto que, algumas de suas propostas são utilizadas até os dias atuais). Lewis apresentou a primeira proposta de sua teoria ácido-base como parte de sua teoria do par eletrônico, criada para explicar a ligação química. Lewis (1923) discutia reações em que ocorre a dissociação de moléculas em íons ou ocorre a associação entre íons e moléculas, nas quais as forças eletrostáticas eram importantes. Os exemplos citados foram:

$$
\mathrm{NH}_{3}=\mathrm{NH}^{-}+\mathrm{H}^{+} \text {e } \mathrm{NH}_{3}+\mathrm{H}^{+}=\mathrm{NH}{ }^{+} \text {. }
$$

Entre tais reações se encontravam as dissociações de ácidos e as bases. A dissociação foi entendida como uma disputa pelo par eletrônico da ligação, o qual ficava com uma das partes dissociadas. Portanto, podia-se deduzir que a associação consistia na formação de uma ligação pela união de um íon positivo ao par eletrônico da outra parte, fosse um íon negativo ou uma molécula. Lewis (1923) reconheceu-se em débito com Werner em relação ao esclarecimento das ideias fundamentais acerca da valência, citando nominalmente seu livro de Química Inorgânica, donde se pode concluir que tinha conhecimento dos conceitos de ácido e base de Werner.

Lewis (1923) criticou as definições de ácido e base de Arrhenius e do sistema solvente por sua pouca generalidade, e propôs novas definições de ácidos e bases que não dependessem da presença de prótons nem envolvessem reações com o solvente (citadas acima). Em dado trecho, também definiu "uma base como uma substância que adiciona íon hidrogênio" (p. 141), produzindo uma grande similaridade com as definições de Lowry e Brönsted.

Quinze anos depois, Lewis (1938) retomou essa discussão em artigo específico sobre o tema, no qual creditou a introdução das denominações doador e aceptor de 
elétrons a Sidgwick e reescreveu suas definições de ácido e base em termos moleculares:

uma molécula básica é aquela que tem um par de elétrons que pode entrar na camada de valência de outro átomo; uma molécula ácida é aquela que é capaz de receber tal par de elétrons na camada de um de seus átomos (Lewis, 1938, p. 294).

Lewis (1938) reconheceu as bases de Brönsted como exemplos da sua concepção de base, mas não citou o conceito de base de Lowry, nem o de Werner. Criticou a definição de ácido como composto que contém hidrogênio como demasiado restrita. Conforme apontado por Jensen (2016a) sua concepção de ácido resultou da percepção de que muitas outras espécies químicas (por exemplo, íons Ag+ (Lewis, 1938, p. 297)) agiam como aceptores de par de elétrons, similarmente ao íon hidrogênio.

Em meados da década de 1960, Ralph Pearson introduziu os conceitos de ácidos e bases duros e moles para esclarecer tendências de reações de compostos segundo o conceito de Lewis. Segundo o autor,

Em termos de equilíbrios, ao invés de taxas, verifica-se que diversos substratos ácidos enquadram-se em duas categorias: aqueles que se ligam fortemente à base, as quais estão fortemente ligadas ao próton, isto é, são básicos no sentido usual; aqueles que se ligam fortemente a bases altamente polarizáveis ou insaturadas, que geralmente têm uma basicidade de próton desprezível. A divisão nessas duas categorias não é absoluta e casos intermediários ocorrem, mas a classificação é razoavelmente nítida e parece ser bastante útil. (...) as bases podem ser divididas em duas categorias: aquelas que são polarizáveis ou "moles" e aquelas que não são polarizáveis, ou "duras" (Pearson, 1963, p. 3533).

A teoria de Pearson é empregada fortemente na Química de Coordenação para explicação da estabilidade dos complexos. Entretanto, seus conceitos de ácido e base são apenas subcategorias do conceito de Lewis.

\section{Contribuições para o Ensino de Química}

No intuito de contribuir para um ensino não fragmentado dos conceitos de ácido, álcali e base, propomos que se acompanhe a sequência de seu desenvolvimento histórico-cultural, explicitando os problemas que deram origem aos conceitos e os argumentos empregados na sua elaboração. Cremos que esse tipo de ensino também possa contribuir para superar concepções alternativas de estudantes (Pan, \& Henriques, 2015).

O ensino pode ser iniciado com a apresentação da origem dos termos ácido e álcali, seguida da experimentação da sensação gustativa de azedo e amargo, empregando materiais comestíveis ácidos e alcalinos. O problema a ser resolvido é a classificação dos materiais por meio do sabor. (É preciso notar o perigo da ingestão de materiais como método para classificação de materiais em geral.)

Dois aspectos dessas experiências que merecem discussão pela importância geral na elaboração de conceitos são as atividades de expressar linguisticamente as características dos sabores azedo e amargo e de selecionar um conjunto de características 
do sabor azedo e do sabor amargo que abranja todos os materiais experimentados. As dificuldades em selecionar palavras que transmitam os sabores específicos experimentados podem ajudar a compreender as dificuldades de elaboração dos conceitos dos adjetivos ácido e alcalino e, consequentemente, dos conceitos material de sabor azedo e material de sabor amargo. Também podem explicitar as dificuldades para decidir a inclusão, ou não, de um novo material na classe desses materiais, posto que, para tanto, precisam apresentar as mesmas características.

A discussão dos conceitos que cada estudante compreende quando ouve ou lê os termos ácido, azedo, álcali e amargo, chamando-se a atenção para os aspectos externos (públicos, comuns e idiossincráticos) e internos (sensações, percepções, sentimentos, recordações), pode contribuir para a conscientização da relação entre pensamento e linguagem via conceito (Quílez-Pardo, 2016; Vigotski, 2009).

A etapa seguinte do ensino vai tratar das interações entre materiais ácidos e outros materiais, especialmente, os alcalinos. A caracterização de reações entre ácidos e álcalis pode ser feita por experiências que produzam aquecimento perceptível, liberação de gases (efervescência), mudanças de cor. Pode-se recorrer a exemplos de reações historicamente situados nos séculos XVII e XVIII ou a experiências com materiais caseiros (Whetzel, 1999).

Um modo de ensinar a reação de neutralização (Nascimento, \& Santos, 2019) é empregar o teste do sabor para demonstrar e acompanhar a alteração da solução à medida que ácido e álcali vão reagindo. $O$ conceito de neutralização também requer o conceito de sal do século XVII (não elaborado neste artigo) para se chegar à proposição da complementaridade de ácidos e álcalis como seus elementos formadores. Esse ponto se articula à discussão teórica do conceito de elemento constituinte dos materiais (Oki, 2002), abrindo possibilidades para discussões acerca das propostas dos gregos e de Paracelso, vigentes na Europa de então.

Também é possível fazer uma articulação entre o papel dos ácidos e álcalis na explicação iatroquímica da digestão e na explicação atual. Um ponto notável é a presença de resquícios da teoria fisiológica ácido-álcali na interpretação trivial de incômodos no estômago, atribuídos ao excesso de acidez, e sua cura pela ingestão de álcalis. Tais resquícios também são encontrados na interpretação da origem das doenças em geral, conforme se pode constatar pela quantidade de sítios na rede mundial de computadores acerca da importância de alimentos acidificantes e alcalinizantes para a saúde.

Um aspecto essencial a ser discutido é o aumento da especificidade dos novos conceitos de ácido e álcali ao se juntar outras características ao sabor, o que possibilitou diferente compreensão e explicação do mundo. Entretanto, essas conceituações de ácido e álcali sofreram críticas: várias das suas características não tinham abrangência e apresentavam exceções, o que se constituiu em problemas. Por isso, faz-se necessário experimentar reações que demonstrem as exceções apontadas.

Outros aspectos que podem ser relacionados ao ensino dos ácidos e álcalis nesta etapa são: a precisão dos experimentos, o emprego de átomos na explicação de reações 
químicas, o processo de disseminação das informações científicas entre os estudiosos no século XVII.

O ensino do conceito de base se constitui em um bom exemplo da elaboração (simples) de um conceito de natureza teórica (Hardy-Vallée, 2013). O argumento tem como premissa o fato de que materiais de diferentes classes - álcalis, metais, terras e óleos - neutralizavam ácidos, de modo que tal característica foi utilizada na caracterização de um conceito aglutinador: a base (ou base salificável, conforme Lavoisier). A partir de então, a caracterização dos álcalis tornou-se de menor importância.

A introdução dos conceitos de ácido e base caracterizados por composição química requer uma discussão mais profunda acerca dos elementos que compõem os materiais, o que vai além da exposição aqui apresentada. É necessário ter noção do contexto em que Lavoisier trabalhava para entender o fato de as reações de combustão produzirem ácidos ter se tornado um problema, levando-o a propor seu conceito de ácido como composto de oxigênio com uma base acidificável. Esse problema não costuma ser discutido no ensino da combustão (Medeiros, \& Amaral, 2017). Experiências de combustão de enxofre e carvão são facilmente realizáveis em laboratórios de ensino. Os gases produzidos podem ser recolhidos sobre água para gerar soluções a serem testadas com indicadores ácido-base ou extratos vegetais (Bellettato, 2012).

O pressuposto teórico subjacente ao conceito de Lavoisier era o princípio material acidificante identificado no oxigênio, cuja denominação significa gerador de ácidos. Trata-se de um conceito de ácido mais avançado, já que previu a existência de bases ainda não isoladas, questionou a teoria do flogístico e explicou o calor da reação ácidobase em conjunto com a teoria do calórico.

Embora bem aceito na comunidade dos químicos, a constatação de que alguns materiais reconhecidamente ácidos (por critérios diferentes da composição) eram compostos de oxigênio e de que outros eram compostos de hidrogênio levou à proposição de dois tipos de ácidos: hidrácidos e oxiácidos. Porém, a classificação de materiais por meio da composição elementar tinha vindo para ficar.

Os conceitos seguintes de ácido e de base, formulados por Arrhenius, não surgiram das limitações de conceitos anteriores, mas da interpretação teórica da condutividade de soluções eletrolíticas de sais, ácidos e bases. Por isso, o ensino dos conceitos de ácido e de base de Arrhenius (e subsequentes) requer conhecimento de modelo atômico estruturado, de ligações químicas, de soluções, de células eletroquímicas, além do conceito de neutralização ácido-base. Experiências de neutralização ácido-base em solução para medida da energia liberada podem ser realizadas com calorímetros caseiros. Porém, medidas de condutividade elétrica requerem equipamentos específicos, além de conhecimentos teóricos sobre eletricidade, para compreensão do processo de medição.

A partir desse ponto do ensino se faz necessária ao estudante a compreensão de que a Química se constitui no entrelaçamento de muitos conceitos elaborados por uma grande quantidade de estudiosos para formar um todo complexo, porém sistematizado. 
No dizer de Luria (1991, p. 73): “a experiência de toda a humanidade acumulada no processo da história social".

Os conceitos de ácido e de base subsequentes se apoiaram nos conceitos de Arrhenius ou tiveram como objetivo superar suas limitações. Por isso ele é a base para o ensino deste tema.

O ensino dos solvo ácidos e bases pode ser realizado por analogia com os conceitos de ácidos e bases de Arrhenius para outros solventes, pois eles mantiveram a característica da dissociação ampliada para solventes não aquosos. Uma vez que os íons produzidos por cada solvente matriz têm composições distintas - não se restringindo a $\mathrm{H}^{+} \mathrm{e}^{-} \mathrm{H}^{-}$ o critério de composição elementar também foi ampliado. Porém, substâncias que são ácidos e bases de um sistema não o são em outros, o que constitui uma especificidade desses conceitos. A experimentação com sistemas líquidos não aquosos como amônia, sulfeto de hidrogênio ou ácido sulfúrico é mais complexa e requer laboratórios bem equipados, dificultando seu emprego no ensino.

Os conceitos de Werner introduzem uma diferença: os íons $\mathrm{H}^{+} \mathrm{e} \mathrm{OH}^{-}$não são produzidos pela dissociação de ácidos e bases, mas por suas reações com água. Os conceitos de Michaelis incluem os dois casos: dissociação e reação com água. $\mathrm{O}$ ensino dos conceitos desses dois químicos requer mais argumentação teórica do que experimentação. É importante ter domínio das teorias empregadas na elaboração dos conceitos para alcançar sua aprendizagem.

Na sequência, ensinam-se os conceitos de Lowry e de Brönsted, cujas formulações finais são similares, embora provenientes de distintos problemas e argumentos, os quais devem ser apresentados. Note-se que, para Lowry e Brönsted, ácidos eram caracterizados por se dissociarem em íons hidrogênio em quaisquer solventes, incluindo os ácidos de Arrhenius como o caso particular da água como solvente. As bases, porém, eram caracterizadas por se associarem com os íons hidrogênio em quaisquer solventes, distinguindo-se das bases de Arrhenius.

No modelo ionotrópico ocorre uma inversão: as bases que se dissociam em íons quaisquer e os ácidos correspondentes se associam aos mesmos íons. Uma discussão das semelhanças e diferenças entre os conceitos ionotrópicos, os de Brönsted-Lowry e aqueles dos sistemas solventes pode ser instrutiva no sentido de compreender como as elaborações conceituais podem se imbricar.

Por fim, ensinam-se os conceitos de Lewis e de Pearson, que se baseiam em reações de associação e são caracterizados estruturalmente. Cabe discutir a analogia entre o par eletrônico e um íon na comparação entre os conceitos de Lewis e outros conceitos. De fato, algumas comparações foram feitas na literatura de Ensino de Química (Paik, 2015), porém sem a devida profundidade conceitual.

A partir dos conceitos de Arrhenius, o nível de abstração vai crescendo: as características incorporam conceitos teóricos e entidades não observáveis (reações de dissociação, íons, ligações químicas, solvatação) que possuem menos concretude do que propriedades sensíveis (sabor, efervescências, mudanças de cor); as relações entre os 
aspectos observáveis e os não observáveis dos conceitos são complexas e exigem o apoio em outras ideias abstratas e fatos não necessariamente relacionados ao tema em foco (teoria atômica, ligação química, eletroquímica). Note-se, ainda, que à medida que a abstração vai crescendo, também aumenta a quantidade de conceitos teóricos empregados na formulação dos conceitos de ácido e base e a quantidade dos materiais que podem ser incluídos nos conceitos, embora a quantidade de características empíricas não tenha aumentado.

Atualmente, ácido ou base são caracterizados empiricamente pelo valor do $\mathrm{pH}$ do material ou de suas soluções. Segue-se a concepção teórica de neutralização: todo ácido pode ser neutralizado por base e vice-versa. A reação de neutralização ganhou importância maior na elaboração dos conceitos de ácido e base de Lowry, Brönsted, LuxFlood, Usanovich, Lewis e Pearson, que não geram os mesmos tipos de produtos (Lima, \& Moradillo, 2019). Embora teoricamente mais complexos, os conceitos pós-Arrhenius adotaram características que incluíam mais e mais casos, de modo que adquiriram mais generalidade. Consequentemente, perderam seu poder de discriminar materiais, o que os enfraqueceu enquanto conceitos classificatórios.

Um aspecto notável é que os ácidos carboxílicos mantiveram sua definição em termos estruturais e, desse modo, sua capacidade de discriminação e classificação de substâncias.

\section{Conclusões}

A História da Química nos mostra que os conceitos de ácido e base/álcali se desenvolveram por fases, gerados a partir de uma diversidade dos problemas, empregando uma variedade de características. É notório que, a partir do final do século XVIII, os diferentes conceitos de ácido e base foram elaborados em conexão com aqueles que os antecederam: cada novo par de conceitos acarretou problemas cuja tentativa de solução produziu mudanças conceituais sucessivas.

De modo muito sucinto, as expressões ácido e base foram mudando de conceito ao longo do tempo, passando de empíricos a teóricos, reduzindo a quantidade de características e adquirindo mais e mais abstração e generalidade. Consequentemente, eles perderam seu poder de discriminar materiais, o que os enfraqueceu enquanto conceitos classificatórios.

Portanto, estamos em condições de responder positivamente à nossa questão de pesquisa: sim, o desenvolvimento histórico dos conceitos de ácido e base pode contribuir para superar a fragmentação constatada no seu ensino, explicitando as razões para sua elaboração e as relações entre os diferentes conceitos ao longo do tempo. Tal contribuição está vinculada à concepção histórico-cultural de conceito e de desenvolvimento psicológico. As implicações para o ensino sugerem uma sequência que entendemos como mais lógica dos conceitos de ácido e base, à medida que esclarece os vínculos entre os sucessivos conceitos.

O próximo passo a ser dado é a elaboração de uma proposta didática que considere 
os vínculos existentes entre cada diferente par de conceitos e a correspondente investigação da aprendizagem dos estudantes relativa a: processos de elaboração conceitual e suas relações; características atribuídas aos materiais, tanto empíricas quanto teóricas; caráter teórico e abstrato dos conceitos; graus de generalidade dos conceitos associados à sua capacidade de discriminação e sua utilidade para a classificação das substâncias. Para tanto, os aspectos relativos a cada fase conceitual podem ser mais detalhados com o auxílio das referências, ou podem ser limitados em função de se pretender trabalhar um ou outro conceito específico.

Nosso relato também pode se constituir na base para a elaboração de materiais didáticos tais como: textos, experimentos, debates, mapas conceituais etc., para uso em disciplinas de Química e/ou História da Química e Ensino de Química.

O fato é que, para alcançar uma aprendizagem profunda dos conceitos de ácido e base, é preciso conhecer os problemas que lhes deram origem e suas tentativas de solução, incluindo-se os raciocínios argumentativos que produziram cada par de novos conceitos.

\section{Referências}

Abbagnano, N. (2007). Dicionário de Filosofia. Martins Fontes.

Abegg, R. (1907). The Electrolytic Dissociation Theory. John Wiley \& Sons. Recuperado de https://archive.org/details/electrolyticdiss00abegrich/page/n1

Acid (2019). In Merriam-Webster: dictionary. Recuperado de https://www.merriamwebster.com/dictionary/acid

Acide. (1751-1765). In D. Diderot, \& J. R. D’Alembert, Encyclopédie ou Dictionnaire Raisonné des Sciences, des Arts et des Métiers (Tome premier: A-Azyme, pp. 97-100). Breton. Recuperado de https://gallica.bnf.fr/ark:/12148/bpt6k50533b/f156n4.texteBrut

Acide. (2013). In CNRTL - Centre National de Ressources Textuelles et Lexicales. Recuperado de https://www.cnrtl.fr/etymologie/acide

Ácido. (2001). In A. Houaiss, \& M. S. Villar. Dicionário Houaiss da Língua Portuguesa (p. 56). Objetiva.

Álcali. (1999). In A. B. H. Ferreira. Novo Aurélio Século XXI: o dicionário da língua portuguesa (3a ed., p. 86). Nova Fronteira.

Álcali (2001). In A. Houaiss, \& M. S. Villar. Dicionário Houaiss da Língua Portuguesa (p. 140). Objetiva.

Alcali. (2013) In CNRTL - Centre National de Ressources Textuelles et Lexicales. Recuperado de: https://www.cnrtl.fr/etymologie/alcali

Alkali. (2019) In Merriam-Webster: dictionary. Recuperado de https://www.merriamwebster.com/dictionary/alkali 
Alkali. (1751-1765). In D. Diderot, \& J. R. D’Alembert, Encyclopédie ou Dictionnaire Raisonné des Sciences, des Arts et des Métiers (Tome premier : A-Azyme, p. 273). Breton. Recuperado de https://gallica.bnf.fr/ark:/12148/bpt6k50533b/f156n4.texteBrut

Alkalies. (1929). In D. Bailey, \& K. Bailey, An Etymological Dictionary of Chemistry and Mineralogy (p.7). Edward Arnold.

Arrhenius, S. (1884). Recherches sur la Condutibilité Galvanic des Electrolytes. (Mémoire présenté a l'Acad. des Sciences de Suède le juin de 1883). Kongl. Boktrykeriet. Recuperado de: https://archive.org/details/recherchessurla00arrhgoog/page/n5

Arrhenius, S. (1887a). Über die Dissociation der in Wasser gelösten Stoffe. Zeitschrift für Physikalische Chemie, 1, 631-648. https://doi.org/10.1515/zpch-1887-0164

Arrhenius, S. (1887b). On the Dissociation of Substances Dissolved in Water. 1887A (Partial translation of Über die Dissociation der in Wasser gelösten Stoffe. Zeitschrift für Physikalische Chemie, 1, 631-648). Recuperado de https://www.chemteam.info/ChemHistory/Arrhenius-dissociation.html

Arrhenius, S. (1902). Textbook of Electrochemistry. Longmans, Green. Recuperado de https://archive.org/details/textbookofelectr00arrhuoft/page/n6

Arrhenius, S. (1903). Development of the Theory of Electrolytic Dissociation. (Nobel Lecture, December, 1903). Recuperado de https://www.nobelprize.org/uploads/2018/06/ arrhenius-lecture.pdf

Arrhenius, S. (1912). Electrolytic dissociation. The Journal of the American Chemical Society, 34(4), 353-363. https://doi.org/10.1021/ja02205a001

Atkins, P., Jones, L., \& Laverman, L. (2018). Princípios de Química (5a ed.). Bookman.

Baker Jr., A. A. (1964). A history of indicators. Chymia, 9, 147-167. https://doi. org/10.2307/27757238

Bardez, E. (2012). Lacido-basicité: des observations aux concepts, les étapes-clés du debut du XIX siècle. Bulletin de la Sabix, 50, 15-29. Recuperado de http://journals. openedition.org/sabix/104

Bardin, L. (2002). Análise de Conteúdo. Edições 70.

Bell, R. P. (1947). The use of the terms acid and base. Quarterly Reviews Chemical Society, 1(2), 113-125. https://doi.org/10.1039/QR9470100113

Bellettato, R. D. (2012). Utilização de indicadores orgânicos de $\mathrm{pH}$ no ensino de ácidos e bases: considerando alguns aspectos históricos. História da Ciência e Ensino: construindo interfaces, 6, 71-77. Recuperado de: https://ken.pucsp.br/hcensino/article/ viewFile/12952/9440.

Beltran, M. H. R., Saito, F., \& Trindade, L. S. (2014). História da Ciência para Formação de Professores. Editora Livraria da Física. 
Benveniste, E. (1976). Problemas de Linguística Geral. Nacional/Edusp.

Boyle, R. (1664). Experiments and considerations touching colours. In: P. SHAW (Ed.) (1725). The Philosophical Works of the Honourable Robert Boyle Esq. (Vol. II). W. and J. Innis, J. Osborn and T, Longman Recuperado de https://archive.org/details/ philosophicalwo01boylgoog/page/n4

Boyle, R. (1675). Experiments, notes etc. about the mechanical origine or production of divers particular qualities: among which is inserted a discourse of the imperfection of chymist's doctrine of qualities; together with some reflections upon the hypothesis of alkali and acidum. Davis Bookseller. Recuperado de: https://archive.org/details/ experimentsnotes00boyl/page/n8

Boas, M. (1956). Acid and alkali in seventeenth century chemistry. Achives Internationales d'Histoire des Sciences, 9, 13-28.

Brock, W. H. (2000). The Chemical Tree: a History of Chemistry (2a ed.). W. W. Norton.

Brönsted, J. N. (1923). Einige Bemerkungen über den Begriff der Säuren und Basen. Recueil Des Travaux Chimiques Des Pays-Bas, 42(8), 718-728. https://doi.org/10.1002/ recl.19230420815

Carrièrre, J. (1893). Berzelius und Liebig: ihre Briefe von 1831-1845. München: J. F. Lehmann. Recuperado de: https://archive.org/search.php?query=Berzelius\%20und\%20 Liebig\%3A\%20ihre\%20Briefe\%20von\%201831-1845

Chang, R., \& Golsby, K. A. (2013). Química (11a ed.). AMGH.

Chagas, A. P. (2000). O ensino de aspectos históricos e filosóficos da Química e as teorias ácido-base do século XX. Química Nova, 23(1), 126-133. http://dx.doi.org/10.1590/ S0100-40422000000100023

Secretaria de Educação Básica. (2006). Ciências da Natureza, Matemática e suas Tecnologias. (Orientações curriculares para o ensino médio, volume 2). Ministério da Educação.

Crosland, M. (1973). Lavosier's theory of acidity. Isis, 64(3), 306-325. http://dx.doi. org/10.1086/351125

Crosland, M. P. (1978). Historical Studies in the Language of Chemistry. Dover.

Dascal, M. (2006). Interpretação e Compreensão. Ed. Unisinos.

Debus, A. G. (2002). The Chemical Philosophy. Dover.

Eco, U. (2009). Tratado Geral de Semiótica (4a ed.). Perspectiva.

Ferrater Mora, J. (1964). Diccionario de Filosofía (5a ed.). Sudamericana.

Ferreira, A. A. L. (2008). O múltiplo surgimento da Psicologia. In A. M. Jacó-Vilela, A. A. L. Ferreira, \& F. T. Portugal (Org.), História da Psicologia (2a ed.). NAU. 
Ferreira, A. M. A. (2013). Prefácio. In B. Hardy-Vallée, Que É um Conceito. Parábola. Flood, H. (1947). The acidic and basic properties of oxides. Acta Chemica Scandinavica, 1(6), 592-604. https://doi.org/10.3891/acta.chem.scand.01-0592

Fonseca, M. R. M. (2016). Química. Ática.

Franklin, E. C. (1905). Reactions in liquid ammonia. Journal of the American Chemical Society, 27(7), 820-851. https://doi.org/10.1021/ja01985a002

Franklin, E. C. (1912). The ammonia system of acids, bases and salts. Journal of the Washington Academy of Sciences, II(9), 215-218. Recuperado de https://www.jstor.org/ stable/24520758

Franklin, E. C. (1924). Systems of acids, bases and salts. Journal of the American Chemical Society, 46(10), 2137-2151. https://doi.org/10.1021/ja01675a001

Gay-Lussac, L. J., \& Thenard, L. J. (1809). De la nature et des propriétés de l'acide muriatique et de l'acide muriatique oxygéné. In Mémoires de Physique et de Chymie, de la Société d'Arcueil (Tome II, pp. 339-353). Paris: Bernard. Recuperado de https://gallica. bnf.fr/ark:/12148/bpt6k1050356z

Geoffroy, E-F. (1741). Table des diferentes rapports observés en Chimie entre differentes substances. In Histoire de l'Academie Royale des Sciences (Année MDCCXVIII, pp.202-212). De l'Imprimerie Royale. Recuperado de https://gallica.bnf.fr/ark:/12148/ bpt6k3519v?rk=64378;0

Germann, A. F. O. (1925). A general theory of solvent systems. Journal of the American Chemical Society, 47(10), 2461-2468. https://doi.org/10.1021/ja01687a006

Goldfarb, A. M. A. (2005). Da Alquimia à Química. Landy.

Gutmann, V. (1968) Coordination Chemistry in Non-Aqueous Solutions. New York: Spinger-Verlag.

Hardy-Vallée, B. (2013). Que É um Conceito? Parábola.

Ihde, A. J. (1984). The Development of Modern Chemistry. Dover.

Jensen, W. B. (2006). The origin of the "term base". Journal of Chemical Education, 83, 1130. https://doi.org/10.1021/ed083p1130

Jensen, W. B. (2016a). Lewis Acid-Base Theory I: Historical Development. In W. B. Jensen. Collected Papers (Volume 3: Acid-Base Chemistry and Related Topics, pp. 1-5). Cincinnati: University of Cincinnati.

Jensen, W. B. (2016b). History and the teaching of chemistry. A tribute to Thomas Lowry's textbook "Historical Introduction to Chemistry". Educación Química, 27(3), 175-181. https://doi.org/10.1016/j.eq.2016.05.001

Jevons, F. R. (1962). Boerhaave's Biochemistry. Medical History, 6(4), 343-362. Recuperado de https://www.ncbi.nlm.nih.gov/pmc/articles/PMC1034758/pdf/ 
medhist00165-0047.pdf

Kauffman, G. B. (1973). Alfred Werner's theory of acids, bases, and hydrolysis. Ambix, 20(1), 53-66. http://dx.doi.org/10.1179/amb.1973.20.1.53

Lavoisier, A-L. (2007). Tratado Elementar de Química. Madras.

Leicester, H. M. (1956). The Historical Background of Chemistry. Dover.

Le Grand, H. E. (1972). Lavosier's oxygen theory of acidity. Annals of Science, 29(1), 1-18. http://dx.doi.org/10.1080/00033797200200331

Le Grand, H. E. (1974). Determination of the composition of the fixed alkalis 17891810. Isis, 65(1), 59-65. https://doi.org/10.1086/351217

Lewis, G. N. (1923). Valence and the Structure of Atoms and Molecules. New York: The Chemical Catalog Company.

Lewis, G. N. (1938). Acids and bases. Journal of the Franklin Institute, 226(3), 293-313. https://doi.org/10.1016/S0016-0032(38)91691-6

Liebig, J. (1840). Traité de Chimie Organique (Tome premier). Fortin, Masson. Recuperado de: https://gallica.bnf.fr/ark:/12148/bpt6k91853v.texteImage

Lima, C., Moradillo, E. F. (2019). Ácidos e bases nos libros didáticos: ainda duas das quatro funções da Química Inorgânica? Química Nova na Escola, 41(3), 242-247. http:// dx.doi.org/10.21577/0104-8899.20160167.

Lopes, C. V. M. (2009). Modelo Atômicos no Início do Século XX: da física clássica à introdução da física quântica. (Tese de Doutorado em História da Ciência). Pontifícia Universidade Católica de São Paulo, São Paulo.

Lowry, T. M. (1923a). The uniqueness of hydrogen. Journal of the Society of Chemical Industry, 42(3), 43-47. https://doi.org/10.1002/jctb.5000420302

Lowry, T. M. (1923b). Co-ordination and acidity. Journal of the Society of Chemical Industry, 42(44), 1048-1052. https://doi.org/10.1002/jctb.5000424402

Luder, W. F. (1940). The electronic theory of acids and bases. Chemical Reviews, 27(3) 547-583. https://doi.org/10.1021/cr60088a003.

Luria, A. R. (1979). Curso de Psicologia geral. Civilização Brasileira.

Luria, A. R. (1991). Curso de Psicologia Geral (v. 1, 2a ed.). Civilização Brasileira.

Lux, H. (1939). "Sauren" und "Basen" im Schmelzfluss: die Bestimmung der Sauerstoffionen-Konzentration. Zeitschrift für Elektrochemie und Angewandte Physikalische Chemie, 45(4), 303-309. https://doi.org/10.1002/bbpc.19390450405

Macquer, P. J. (1756). Elements de chymie-theorique (9a ed.). Jean Thomas Hérissant. Recuperado de https://archive.org/details/BIUSante_pharma_011356/page/n23 
Macquer, P. J. (1778). Dictionnaire de Chymie (Tome Premier). Didot. Recuperado de https://archive.org/details/dictionnairedech01macq/page/n8

Medeiros, S. M. A., Amaral, E. M. R. (2017). A reação química de combustão nos artigos da Revista Química Nova na Escola. In Atas do XI Encontro Nacional de Pesquisa em Educação em Ciências. Florianópolis: Abrapec. Recuperado de: abrapecnet.org.br/ enpec/xi-enpec/anais/resumos/R1957-1.pdf.

Merriam-Webster: dictionary (2019b). Recuperado de https://www.merriam-webster. com/dictionary/alkali

Michaelis, L (1926). Hydrogen Ion Concentration (Volume I). Bailliere, Tindall \& Cox. Recuperado de https://archive.org/details/in.ernet.dli.2015.152659

Nascimento, G. S.; Santos, B. F. (2019). Aprendizagem dos conceitos de ácidos e bases em um estudo sobre a linguagem. Química Nova na Escola, 41(2), 179-189. http://dx.doi. org/10.21577/0104-8899.20160136.

Novais, V. L. D., \& Antunes, M. T. (2016). Vivá:Química. Curitiba: Positivo.

Nunes, A. O., Dantas, J. M., de Oliveira, O. A., \& Hussein, F. R. G. S. (2016). Revisão no campo: o processo de ensino-aprendizagem dos conceitos ácido e base entre 1980 e 2014. Química Nova na Escola, 38(2), 185-196. http://dx.doi.org/10.5935/01048899.20160025

Oki, M. C. M. (2002). O conceito de elemento da antiguidade à modernidade. Química Nova na Escola, 16, 21-25.

Paik, S-H. (2015). Understanding the relationship among Arrhenius, Brønsted-Lowry, and Lewis theories. Journal of Chemical Education, 92(9) 1484-1489. https://doi. org/10.1021/ed500891w.

Pan, H., Henriques, L. (2015). Students' alternate conceptions on acids and bases. School Science and Mathematics, 115(5), 237-243. https://doi.org/10.1111/ssm.12124.

Partington, J. R. (1961). A History of Chemistry (Volume 2). London: Macmillan.

Partington, J. R. (1962). A History of Chemistry (Volume 3). London: Macmillan.

Partington, J. R. (1964). A History of Chemistry (Volume 4). London: Macmillan.

Pearson, R.G. (1963). Hard and soft acids and bases. Journal of the American Chemical Society, 85(22), 3533-3539. https://doi.org/10.1021/ja00905a700

Quílez-Pardo, j. (2016) - El lenguaje de la ciencia como obstáculo de aprendizaje de los conocimientos científicos e propuestas para superarlo. Revista Brasileira de Pesquisa em Ensino de Ciências, 16(2), 449-476.

Rouelle, G-F. (1748). Memoires sur les sels neutres. In Histoire de l'Academie Royale des Sciences (Année MDCCXLVIII, pp. 353-365). De l'Imprimerie Royale. Recuperado de https://gallica.bnf.fr/ark:/12148/bpt6k3542h 
Rouelle, G-F. (1759). Memoires sur les sels neutres. In Histoire de l'Academie Royale des Sciences (Année MDCCLIV, pp. 572-588). Paris: De l'Imprimerie Royale. Recuperado de https://gallica.bnf.fr/ark:/12148/bpt6k3557b

Siegfried, R. (2002). Form Elements to Atoms: a history of chemical composition. Philadelphia: American Philosophical Society.

Silva, M. P., \& Santiago, M. A. (2012). Proposta para o ensino dos conceitos de ácidos e bases: construindo conceitos através da história da ciência combinada ao emprego de um software interativo de livre acesso. História da Ciência e Ensino: construindo interfaces, 5, 48-82. Recuperado de: https://revistas.pucsp.br/hcensino/article/view/9263/7343

Souza, C. R., \& Silva, F. C. (2018). Discutindo o contexto das definições de ácido e base. Química Nova na Escola, 40(1), 14-18. http://dx.doi.org/10.21577/0104-8899.20160099 Souza, F. M., \& Aricó, E. M. (2017). Mapa cronológico da evolução das definições ácidobase: um potencial material de apoio didático para contextualização histórica no ensino de química. Educación Química, 28, 2-10. https://doi.org/10.1016/j.eq.2016.09.002

Vigotski, L. S. (2009). A construção de Pensamento e da Linguagem (2a ed.). São Paulo: WMF Martins Fontes.

Werner, A. (1911). New Ideas on Inorganic Chemistry. Longmans, Green. Recuperado de: https://archive.org/details/in.ernet.dli.2015.247392/page/n5

Werner, A. (1913). On the Constitution and Configuration of Higher-Order compounds (Nobel Lecture, Dec 1913). Recuperado de: https://link.springer.com/article/10.1007/ BF02834238.

Whetzel, J. (1999). Sour Science. Science Activities, 35(4), 14-17. https://doi. org/10.1080/00368129909600922.

Whittaker, E. T. (1910). A History of the Theories of Aether and Electricity. Longmans, Green. Recuperado de: https://archive.org/details/historyoftheorie00whitrich/page/n1 
Cintia Maria Carneiro Franco Lima

${ }^{\oplus}$ https://orcid.org/0000-0002-3448-2162 Universidade Federal da Bahia Instituto de Química

Programa de Pós-Graduação em Química Salvador, Bahia, Brasil cintialima.quimica@gmail.com

José Luis de Paula Barros Silva

${ }^{\circledR}$ https://orcid.org/0000-0003-0721-6341

Universidade Federal da Bahia Instituto de Química Departamento de Físico-Química Salvador, Bahia, Brasil joseluis@ufba.br

Submetido em 08 de setembro de 2019

Aceito em 09 de março de 2020 Publicado em 02 de abril de 2020 